\title{
Pure Mucinous Breast Carcinoma: A Favorable Subtype
}

\author{
Meng Yang $^{a} \quad$ Xin Li $^{b} \quad$ Chun-Hong Pang ${ }^{c} \quad$ Lin-Ping Huang ${ }^{a}$ \\ aDepartment of Breast Surgery, Breast Tumor Center, ' Institute of Clinical Science, \\ 'Department of Pathology, China-Japan Friendship Hospital, Beijing, China
}

\section{Keywords}

Breast cancer - Mucinous carcinoma P Prognosis

\section{Summary}

Background: Pure mucinous breast carcinoma is a relatively rare subtype of breast malignancy. This study is to investigate the clinical and pathologic features of pure mucinous breast carcinoma. Patients and Methods: A retrospective review of our database of patients who presented with breast cancer was performed. The medical records of 1,060 patients with invasive breast cancer who underwent surgery were reviewed. Results: 28 patients with pure mucinous breast cancer were identified. The mean age was $55.28 \pm 15.73$ years. 17 patients underwent modified radical mastectomy; 11 underwent breast-conserving therapy. The tumor size was T1 in 19 patients, T2 in 8 patients, and T3 in 1 patient. None of the patients had lymph node metastasis. There was no distant metastasis. 18 were stage I, and 10 were stage II. Estrogen receptor, progesterone receptor, HER-2, and P53 were positive in 96, 93, 0, and 28\%, respectively. Median follow-up was 42 months (range 1-84 months). 1 patient had local recurrence. The overall survival rate was $100 \%$. Conclusion: Pure mucinous breast carcinoma has a favorable prognosis. Less invasive treatment might be optional. Larger data samples with longer followup would be necessary to gain a better understanding of this disease.

\section{Introduction}

Breast cancer is a leading form of malignancy in women [1]. It has different histologic types that reflect not only morphologic features but also biologic characteristics [2]. Mucinous carcinoma is categorized as a special type of breast cancer,

\author{
Schlüsselwörter \\ Mammakarzinom · Muzinöses Karzinom · Prognose
}

\section{Zusammenfassung}

Hintergrund: Das reine muzinöse Mammakarzinom ist eine relativ seltene Form des Brustkrebses. Die vorliegende Studie befasst sich mit den klinischen und pathologischen Eigenschaften dieses Tumors. Patientinnen und Methoden: Unsere Datenbank von Patientinnen, die mit einem Mammakarzinom vorstellig wurden, wurde retrospektiv ausgewertet. Dies umfasste die Krankenakten von 1060 Patientinnen mit invasivem Mammakarzinom, die chirurgisch behandelt worden waren. Ergebnisse: 28 Patientinnen mit reinem muzinösen Mammakarzinom wurden identifiziert. Das mittlere Alter war 55,28 \pm 15,73 Jahre. Bei 17 Patientinnen wurde eine modifizierte radikale Mastektomie durchgeführt; $11 \mathrm{~Pa}-$ tientinnen erhielten eine brusterhaltende Therapie. Die Tumorgröße war T1 bei 19 Patientinnen, T2 bei 8 Patientinnen und T3 bei einer Patientin. Keine der Patientinnen hatte Lymphknotenmetastasen, und es wurden keine Fernmetastasen beobachtet. 18 Patientinnen befanden sich im Stadium I, 10 Patientinnen im Stadium II. Der Östrogenrezeptor-, Progesteronrezeptor-, HER-2- und P53-Status war bei 96, 93, 0 bzw. 28\% positiv. Das mittlere Follow-up war 42 Monate (Spanne 1-84 Monate). Eine Patientin hatte ein Lokalrezidiv. Das Gesamtüberleben war $100 \%$. Schlussfolgerung: Das reine muzinöse Mammakarzinom hat eine günstige Prognose. Weniger invasive Behandlungsansätze könnten unter Umständen in Erwägung gezogen werden. Für ein besseres Verständnis dieser Tumorentität bedarf es größerer Datensätze mit längerem Follow-up.

presenting with a massive production of extracellular mucin. It is divided into 2 subtypes, the pure type and the mixed type [3]. The distinction between the 2 subtypes of pure and mixed mucinous carcinoma is based upon the quantification of cellularity. The pure type consists exclusively of tumor tissue with extracellular mucin production, while the mixed form

\begin{tabular}{ll}
\hline KARGER & $\begin{array}{l}\text { () 2013 S. Karger GmbH, Freiburg } \\
1661-3791 / 13 / 0081-0056 \$ 38.00 / 0\end{array}$ \\
$\begin{array}{l}\text { Fax }+497614520714 \\
\text { Information@Karger.com } \\
\text { www.karger.com }\end{array}$ & $\begin{array}{l}\text { Accessible online at: } \\
\text { www.karger.com/brc }\end{array}$
\end{tabular}

Lin-Ping Huang, MD

Department of Breast Surgery Breast Tumor Center

China-Japan Friendship Hospital

Health Ministry of China, Beijing 100029, China

hlpsurg@sina.com 
also contains an infiltrating ductal epithelial component without mucin [4]. Pure mucinous breast carcinoma (PMBC) is a rare histologic type of mammary neoplasm, representing $1-4 \%$ of all breast cancers. It is associated with a better prognosis than infiltrative ductal carcinoma [4]. In this study, we investigated the clinicopathologic characteristics and treatment patterns for PMBC in our center. Our objective was to further understand the impact of those clinical and pathologic features on the prognosis of PMBC.

\section{Material and Methods}

We retrospectively reviewed the data of 1,060 breast cancer patients who underwent surgery in the Center of Breast Surgery, China-Japan Friendship Hospital, Beijing, China between January 2004 and December 2011. The medical records of patients identified as having received a pathologic diagnosis of PMBC were reviewed. We evaluated age at diagnosis, surgical treatment, tumor size and pathologic grade, hormone receptor and nodal status, and the use of adjuvant chemotherapy, endocrine therapy, and/or radiotherapy. Tumor stage, histological type, and grading were based on the National Comprehensive Cancer Network (NCCN, version 2, 2011) classification. As for immunohistochemistry, we used a primary mouse monoclonal antibody and a secondary antibody from Dako Corp., Glostrup, Denmark. $10 \%$ or more of positively stained cells was used as the cut-off for estrogen receptor (ER), progesterone receptor (PR), and P53 positivity before 2005 , and we used $1 \%$ or more as the cut-off after 2005. HER-2/neu staining was scored from 0 to $3+$, and immunohistochemical staining was considered positive when strong (3+) membranous staining was observed. Clinical follow-up included history taking, physical examination, laboratory tests, and radiology imaging every 6-12 months. Time to follow-up was calculated as time of pathologic diagnosis to most recently identified patient contact or database update, and time to recurrence was calculated as time of pathologic diagnosis to diagnosis of local or distant recurrence.

\section{Results}

Patient and tumor characteristics are presented in table 1. From January 2004 to December 2011, a total 960 patients with invasive breast cancer were reviewed. Of these, 28 (2.6\%) patients with PMBC were identified. All 28 patients were women, of whom $50 \%$ were postmenopausal at the time of diagnosis. The mean age at presentation was $55.28 \pm 15.73$ years (range $32-81$ years). 23 (82\%) patients had a palpable mass in their breast. The laterality of the lesions was left-sided in $15(54 \%)$ patients and right-sided in $13(46 \%)$ patients. Ultrasound examinations revealed a solid hypoechoic mass with posterior echo enhancement in 22 patients (fig. 1). Mammography displayed a well-circumscribed lobulated mass in 9 patients and a calcified mass in 1 patient (fig. 2). All pathologic diagnoses were PMBC which had a mucinous component of more than $90 \%$. The tumor size was T1 in 19 patients, T2 in 8 patients, and T3 in 1 patient. Macroscopically the tumors were well-circumscribed with pushing margins and a typical gelatinous soft cut surface. The microscopic features were small clusters of uniform epithelial cells with mild
Table 1. Clinical and pathological features of pure mucinous breast carcinoma (PMBC)

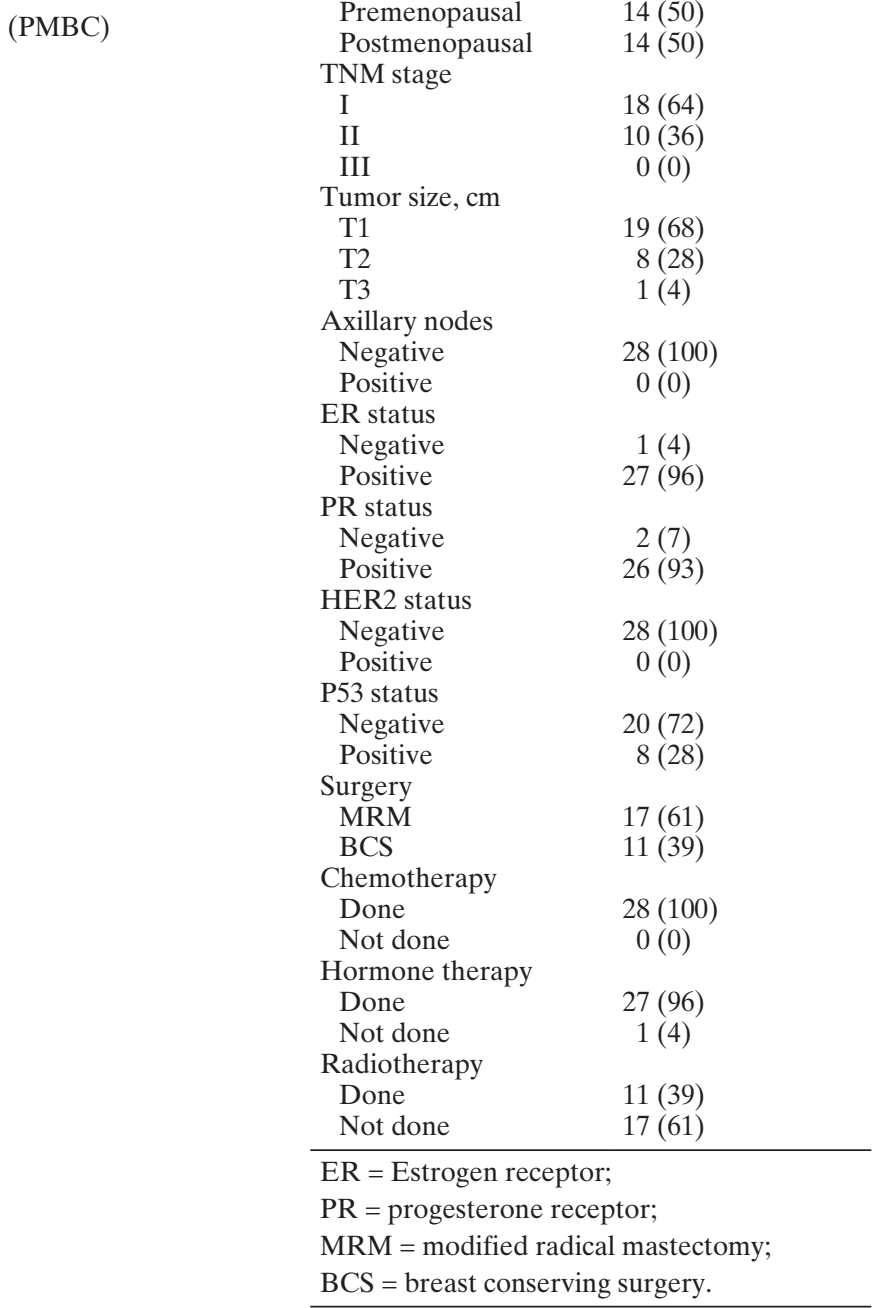

nuclear atypia, floating in abundant 'lakes' of mucus (fig. 3). Delicate bands of fibrovascular connective tissue were often present within the mucus lakes. The cell clusters floating in the mucus may be solid or micropapillary, or form secondary lumens. We did not find any potential ductal carcinoma in situ component in the breast tissue outside of the tumor. 17 (61\%) patients underwent modified radical mastectomy; 11 (39\%) underwent breast-conserving therapy. All patients underwent axillary node dissection. None had lymph node metastasis. There was no distant metastasis either. All patients presented with early stage disease: 18 (64\%) were stage I, and 10 (36\%) were stage II. Regarding adjuvant therapy, all patients received chemotherapy, 27 (96\%) had hormonal therapy, and 11 (39\%) had radiation therapy. ER, PR, HER-2, and P53 were positive in $96,93,0$, and $28 \%$, respectively. Median follow-up was 42 months (range 1-84 months). There was no distant recurrence. 1 (4\%) patient had local recurrence on the chest skin 2 years after surgery. The overall survival rate was $100 \%$. 


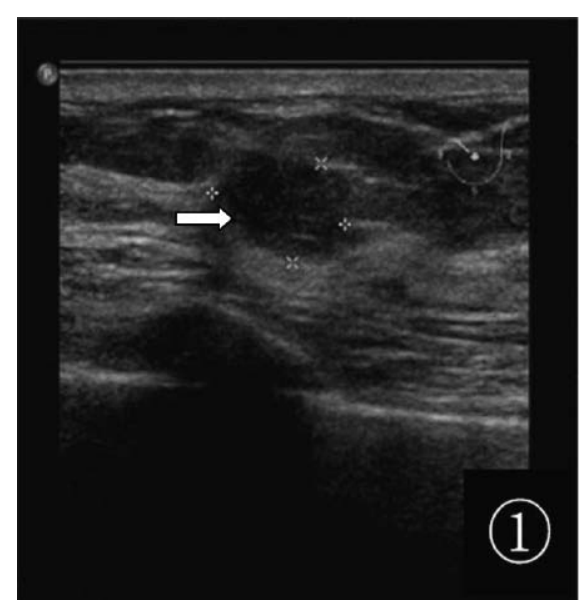

Fig. 1. Ultrasound screen.

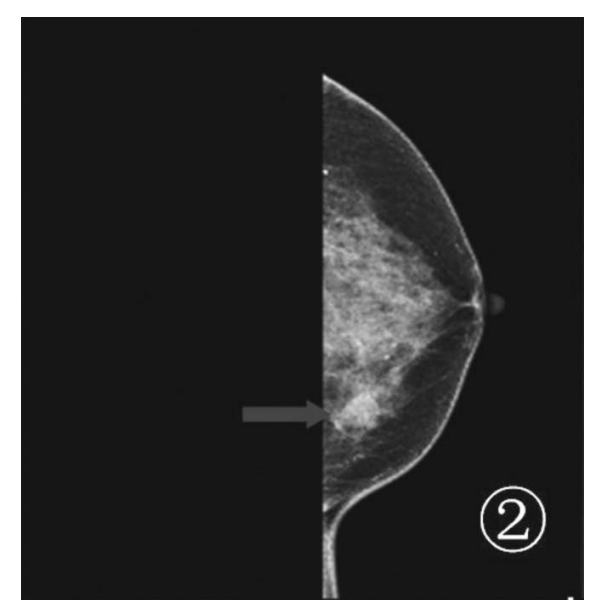

Fig. 2. Mammographic screen.

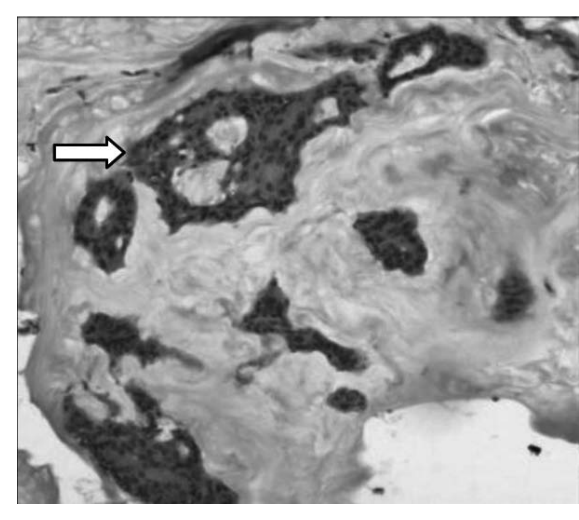

Fig. 3. Original pure mucinous breast carcinoma pathology (magnification $\times 40$; $\mathrm{H} \& \mathrm{E}$ ).

\section{Discussion}

PMBC is a rare disease which mainly occurs in older women. Only $1 \%$ of PMBC patients are younger than 35 years [4]. At our center, the incidence was $2.6 \%$ ( 28 of 1,060$)$, the mean age was $55.28 \pm 15.73$ years, and $12 \%$ ( 3 of 25 ) of patients were younger than 35 years. The age of onset is different from that of Western cases, but similar to that in another report from Asia [5]. The reason is not clear, but it might be due to the breast cancer screening policy in China and genetic or environmental factors in Asia.

PMBC has been reported to have imaging characteristics that may mimic benign lesions, including a well-circumscribed margin and absence of microcalcification [6]. In our data, ultrasound examinations revealed a solid hypoechoic mass with posterior echo enhancement in 22 of 28 patients. Mammography displayed a well-circumscribed lobulated mass in 10 patients, and a calcified mass in 1 patient. The large quantity of mucin may preclude detection of suspicious mammographic findings such as microcalcifications. These findings may mislead physicians and give a benign impression. The combination of a relatively unsuspicious mammography finding and softness upon palpation may increase the incidence of delayed diagnosis [7]. We found $82 \%$ of patients had a palpable mass in their breast, perhaps a reflection of delayed presentation. However, we thought the delay in diagnosis did not lead to women suffering a demonstrable disadvantage since PMBC is characteristically slow growing with a good prognosis, which is consistent with other studies [6].

PMBC displays indolent behavior, and mucin comprises the majority of the tumor volume. We found that the tumor size was $\mathrm{T} 1$ in 19 patients, $\mathrm{T} 2$ in 8 patients, and $\mathrm{T} 3$ in 1 patient. Previous studies found that the size can become very large but potentially not impact survival [7]. The volume of mucin contributes to an overestimation of tumor size, and thus early detection could contribute to the very good prognosis in
PMBC [3]. Previous report demonstrated that no correlation exists between tumor size and prognosis because the tumor size largely depends on the volume of extracellular mucin [7]. Mucins are a family of high-molecular weight, heavily glycosylated proteins [3]. One investigator reported the expression of MUC2 and MUC6 in mucinous carcinoma to be significantly higher than in invasive ductal carcinoma [8]. The overexpression of mucin proteins, especially MUC2 and MUC6, results in the production of excess gel-forming types of mucins, which might act as a barrier to cancerous extension [3]. Mucinous carcinoma tends to grow slowly, but it can sometimes have reached a large size by the time of diagnosis. Presumably one of the reasons might be that its mucinous content does not feel solid or firm upon examination [7]. Axillary lymph node involvement is rare and was detected in $12 \%$ of the patients in the review by Saverio et al. [4] and 14\% in the series by Komenaka et al. [7]. An inverse trend was reported to exist between MUC2 expression and lymph node stage and vascular invasion status [9]. In our series, none of the patients had axillary lymph node metastasis, 18 (64\%) were stage I, 10 $(36 \%)$ were stage II, and only $1(4 \%)$ had local recurrence, which suggests a less aggressive behavior and favorable prognosis. We provided chemotherapy for the patients with low stage and low grade tumors because we were uncertain about the prognosis of PMBC at that time.

In the present study, all tumors had a high proportion of expression of hormone receptors: ER and PR were positive in 96 and $93 \%$ of tumors, respectively, which indicates a better differentiation than the ductal lesions. We used endocrine therapy (tamoxifen or letrozole) for the ER/PR-positive patients. Our results were consistent with previous reports [4]. The HER-2/neu proto-oncogene is amplified and/or overexpressed in approximately $25 \%$ of breast carcinomas; it is associated with poor patient prognosis [10]. In our study, none of the patients were HER-2/neu-positive, which is agreement with other series $[5,10]$. The high rate of hormone receptor 
expression and low rate of HER-2/neu expression suggested a good prognosis and was likely related to advanced age at presentation. Hsu et al. [10] reported a low frequency (9.1\%) of P53 expression, which might contribute to the better prognosis. Our present results showed P53-positive status in 28\% of patients. How P53 is involved in tumorigenesis of PMBC is not clear and requires further study.

In our analysis, 17 (61\%) patients underwent modified radical mastectomy, and 11 (39\%) underwent breast-conserving therapy. The majority of these operations were performed earlier in the reviewed period when mastectomy was still the preferred surgical option. Just as tumor size was not a significant prognostic factor [7], the extent of surgery also did not influence survival. Anan et al. [11] suggested that patients with PMBC, except for those invading the local skin, are suitable candidates for breast-conserving therapy, probably even in the presence of large tumors up to $5 \mathrm{~cm}$ in diameter [11]. All patients underwent axillary node dissection in our review. No lymph node metastasis was found which was consistent with previous reports [12]. Paramo et al. [12] reported that axillary lymph node staging in these patients may not be necessary because PMBC seems not likely to metastasize. The presence of lymph node metastases strongly indicates the presence of a mixed mucinous carcinoma. A recent analysis recommended axillary staging by sentinel lymph node biopsy, and administration of adjuvant radiotherapy and endocrine therapy after breast-conservation for mucinous carcinoma [13]. Park et al. [5] thought that adjuvant chemotherapy could potentially be omitted in cases with favorable risk factors. In our opinion the less invasive treatment for PMBC, such as breast-conserving therapy and sentinel lymph node biopsy, may be optional.
PMBC is associated with outstanding overall and diseasefree survival both in the literature $[4,7]$ and in our review. However some previous series have suggested that the observed favorable 5-year survival is temporary and that PMBC tends to recur after 10 years similar to infiltrating ductal carcinoma [4]. The fact that the tumor displays the ability for late recurrence shows that despite its indolent local behavior, it might become systemic before treatment commences. This indicates that it needs longer to proliferate and manifest clinically, and hence it should be followed-up over a long period of time.

\section{Conclusion}

Collectively, PMBC has a low incidence, small tumor size, benign lesion-like characteristics, low axillary lymph node metastasis, high expression rates of ER and PR, low overexpression of HER-2/neu, low grade, low recurrence rate, and high survival rate. All the above indicate favorable histologic features and a better prognosis. Axillary staging by sentinel lymph node biopsy and administration of adjuvant radiotherapy and endocrine therapy after breast-conservation are recommended. Adjuvant chemotherapy may be omitted in cases with favorable risk factors. Furthermore, larger data samples with longer follow-up are necessary to gain a better understanding of this disease.

\section{Disclosure Statement}

The authors declare no conflict of interest.

\section{References}

1 Jemal A, Bray F, et al.: Global cancer statistics. CA Cancer J Clin 2011;61:69-90.

2 Akiyama F, Horii R: Therapeutic strategies for breast cancer based on histological type. Breast Cancer 2009;16:168-172.

3 Hanagiri T, Ono K, et al.: Clinicopathologic characteristics of mucinous carcinoma of the breast. Int Surg 2010;95:126-129.

4 Saverio SD, Gutierrez J, et al.: A retrospective review with long term follow up of 11,400 cases of pure mucinous breast carcinoma. Breast Cancer Res Treat 2008;111:541-547.

5 Park S, Koo J, Kim JH, Yang WI, Park BW, Lee KS: Clinicopathological characteristics of mucinous carcinoma of the breast in Korea: comparison with invasive ductal carcinoma-not otherwise specified. J Korean Med Sci 2010;25:361368.
6 Dhillon R, Depree P, Metcalf C, Wylie E: Screendetected mucinous breast carcinoma: potential for delayed diagnosis. Clin Radiol 2006;61:423-430.

7 Komenaka IK, El-Tamer MB, Troxel A, HameleBena D, Joseph KA, Horowitz E, Ditkoff BA, Schnabel FR: Pure mucinous carcinoma of the breast. Am J Surg 2004;187:528-532.

8 Matsukita S, Nomoto M, Kitajima S, Tanaka S, Goto M, Irimura T, Kim YS, Sato E, Yonezawa S: Expression of mucins (MUC1, MUC2, MUC5AC and MUC6) in mucinous carcinoma of the breast: comparison with invasive ductal carcinoma. Histopathology 2003;42:26-36.

$\checkmark 9$ Rakha EA, Boyce RW, Abd El-Rehim D, Kurien T, Green AR, Paish EC, Robertson JF, Ellis IO: Expression of mucins (MUC1, MUC2, MUC3, MUC4, MUC5AC and MUC6) and their prognostic significance in human breast cancer. Mod Pathol 2005;18:1295-1304.
10 Hsu YH, Shaw CK: Expression of p53, DCC, and HER2/neu in mucinous carcinoma of the breast. Kaohsiung J Med Sci 2005;21:197-202.

11 Anan K, Mitsuyama S, Tamae K, Nishihara K, Iwashita $\mathrm{T}$, Abe $\mathrm{Y}$, Ihara $\mathrm{T}$, Nakahara $\mathrm{S}$, Katsumoto F, Toyoshima S: Pathological features of mucinous carcinoma of the breast are favourable for breast-conserving therapy. Eur J Surg Oncol 2001;27:459-463.

12 Paramo JC, Wilson C, Velarde D, Giraldo J, Poppiti RJ, Mesko TW: Pure mucinous carcinoma of the breast: is axillary staging necessary? Ann Surg Oncol 2002;9:161-164.

13 Barkley CR, Ligibel JA, Wong JS, Lipsitz S, Smith BL, Golshan M: Mucinous breast carcinoma: a large contemporary series. Am J Surg 2008;196:549-551. 